\title{
Alveolar macrophages lack CCR2 expression and do not migrate to CCL2
}

\author{
Judy M Opalek ${ }^{1,2}$, Naeem A Ali ${ }^{2}$, Jennifer M Lobb², Melissa G Hunter ${ }^{2}$ and \\ Clay B Marsh*2
}

Address: ${ }^{1}$ Department of Pathology, The Ohio State University, Columbus Ohio, USA and ${ }^{2}$ Department of Internal Medicine, Division of Pulmonary and Critical Care Medicine, The Ohio State University and Dorothy M. Davis Heart and Lung Research Institute, Columbus, Ohio, USA

Email: Judy M Opalek - judy.opalek@osumc.edu; Naeem A Ali - naeem.ali@osumc.edu; Jennifer M Lobb - jennifer.lobb@osumc.edu; Melissa G Hunter - melissa.hunter@osumc.edu; Clay B Marsh* - clay.marsh@osumc.edu

* Corresponding author

Published: 22 September 2007

Journal of Inflammation 2007, 4:19 doi:10.1 186/1476-9255-4-19

This article is available from: http://www.journal-inflammation.com/content/4/1/19

(C) 2007 Opalek et al; licensee BioMed Central Ltd.

This is an Open Access article distributed under the terms of the Creative Commons Attribution License (http://creativecommons.org/licenses/by/2.0), which permits unrestricted use, distribution, and reproduction in any medium, provided the original work is properly cited.
Received: I February 2007

Accepted: 22 September 2007

\begin{abstract}
Background: The recruitment of mononuclear cells has important implications for tissue inflammation. Previous studies demonstrated enhanced CCRI and CCR5 expression and decreased CCR2 expression during in vitro monocyte to macrophage differentiation. To date, no study examined the in vivo differences in chemokine receptor expression between human peripheral blood monocytes and alveolar macrophages.
\end{abstract}

Methods: We examined the expression of these receptors in human peripheral blood monocytes and alveolar macrophages using microarray analysis, reverse-transcriptase PCR, flow cytometry and migration analyses.

Results: In contrast to peripheral blood monocytes, alveolar macrophages did not express the CCL2 receptor, CCR2, and did not migrate toward CCL2. In contrast, monocytes and freshly isolated resident alveolar macrophages both migrated towards CCL3. However, up to 6-fold more monocytes migrated toward equivalent concentrations of CCL3 than did alveolar macrophages from the same donor. While peripheral blood monocytes expressed the CCL3 receptor, CCRI, alveolar macrophages expressed the alternate CCL3 receptor, CCR5. The addition of anti-CCR5 blocking antibodies completely abrogated CCL3-induced migration in alveolar macrophages, but did not affect the migration of peripheral blood monocytes.

Conclusion: These data support the specificity of CCL2 to selectively drive monocyte, but not alveolar macrophage recruitment to the lung and CCR5 as the primary macrophage receptor for CCL3.

\section{Background}

Peripheral blood monocytes and alveolar macrophages are similar in function, both physiologically and pathophysiologically. Because monocytes are precursors to tissue macrophages, these cells are often referenced interchangeably. However, these cells have independent functions and are differentially regulated. We hypothesized that differences in receptor expression on each cell type distinguished functional chemokine responsiveness between monocytes and alveolar macrophages. 
To delineate the mechanism regulating peripheral blood monocyte and alveolar macrophage recruitment to the lung, the response of these cells to CCL2 was examined. CCL2, a C-C chemokine, regulates monocyte chemotaxis $[1,2]$, a property shared by several chemokines having adjacent cysteine residues in the $\mathrm{N}$-terminus [3]. Although several chemokines influence monocyte trafficking, CCL2 appears to be critical, as mice deficient in CCL2 have decreased recruitment of monocytes in response to infection and chemotactic stimuli [4] and are protected from models of human disease like pulmonary fibrosis [5]. However, both deficiency and excess of CCL2 are problematic. Mice over-expressing CCL2 have increased numbers of mononuclear cells in affected organs [6], are more susceptible to encephalopathy induced by pertussis toxin [7], and have exacerbated ischemic brain injury in a stroke model [8].

CCL2 specifically binds the surface receptor CCR2, and induces mononuclear cell, but not neutrophil, chemotaxis [3]. Because CCL2 primarily signals via CCR2, expression of this receptor largely regulates CCL2 function. In peripheral blood, CCR2 expression is largely limited to monocytes and some T lymphocytes [9]. CCR2 exists as two RNA splice-variants, named CCR2A and CCR2B. These variants, which differ only in their carboxyl tails [10], both bind CCL2. CCR2B seems to be the predominant variant in monocytes and in monocyte-like cell lines [11]. Mice lacking CCR2 develop normally and have no overt hematopoietic or other phenotypic abnormalities [12], however, they do demonstrate enhanced myeloid progenitor cell cycling and concomitant apoptosis [13]. Of note, CCR2 also recognizes the murine chemokine CCL12, which is important in recruiting fibrocytes to the lung after lung injury for lung repair and remodeling [14]. CCR2 deficient mice, like CCL2 deficient mice, are unable to recruit monocytes to sites of inflammation [15], fail to clear certain intracellular pathogens [12] and are protected from lung fibrosis [16].

CCL2 and/or CCR2 are implicated in the genesis and progression of diseases such as coronary artery disease [17], autoimmune disease [18], and pulmonary fibrosis $[5,16]$. Thus, physiologic regulation of the production, expression and function of CCL2, via CCR2, is critical for host homeostasis. Studies from a number of investigators suggest that CCR2 is down-regulated on the surface of monocytes as they undergo in vitro differentiation to macrophages $[19,20]$. Similar studies evaluating the expression of CCR2 on the surface of native tissue macrophages have not been done.

Comparable to CCL2, CCL3 is another member of the C$\mathrm{C}$ chemokine family and has chemotactic activity for monocytes and macrophages [21]. Although CCL3 aggre- gates at high concentrations, at physiological levels $(<100$ $\mathrm{ng} / \mathrm{ml}$ ) it exists solely as a monomer [22]. Under normal conditions, most hematopoietic cells synthesize and secrete low levels of CCL3. Interestingly, CCL3 secretion by monocytes is increased during monocyte-endothelial interactions mediated by Intracellular Adhesion Molecules (ICAM), and some hypothesize that this enhancement sustains mononuclear phagocyte recruitment [22]. Mice deficient in CCL3 develop normally, but have decreased inflammation to an injurious stimulus and, in response to viral challenge, have reduced viral clearance [23]. Altered expression of CCL3 is implicated in disease states, including atherosclerosis [24], rheumatoid arthritis [25], adult T-cell leukemia [26], and, like CCL2, pulmonary fibrosis $[27,28]$.

CCL3 binds the C-C chemokine receptors CCR1 and CCR5. CCR1 and CCR5 share 55\% amino acid homology [29]. CCR1 is expressed on monocytes, eosinophils, basophils and activated Tlymphocytes, and can also bind CCL5 (RANTES) and the monocyte chemotactic proteins CCL8 (MCP-2) and CCL7 (MCP-3) [30]. CCR1 is rapidly internalized after exposure to its ligand(s) [31].

In contrast to high levels CCR1 expressed by monocytes, CCR5 is preferentially expressed by monocyte-derived macrophages and NK cells [20,32]. CCR5 plays an important role in HIV infection, particularly those caused by R5 ("macrophage-tropic") strains [29]. As evidence of its importance, humans with a specific CCR5 deletion mutation, CCR5- $\Delta 32$, are protected from infection by these HIV strains [33]. CCR5 has been extensively studied in relation to HIV infection and during in vitro monocyte differentiation, but no studies have yet examined CCR5 expression in native alveolar macrophages.

The expression of specific chemokine receptors on alveolar macrophages have not been characterized, though other populations of primary tissue macrophages, like human peritoneal macrophages (PM), express CCR1 and CCR5 [34]. In addition, numerous studies demonstrate that in vitro maturation of blood monocytes to macrophages selectively changes the expression of specific chemokine receptors. For instance, CCR2 expression is reduced as monocytes are cultured, beginning as early as 4 hours [20]. This decline in CCR2 expression continues for up to seven days, at which time no CCR2 is detected [19]. While it is presumed that endogenous maturational events lead to loss of CCR2 expression in monocytes differentiated in vitro, some studies suggest that the loss of CCR2 expression is a direct result of binding secreted CCL2 [9]. In contrast, during in vitro monocyte differentiation, surface expression of CCR1 and CCR5 increase within 24 hours and correlate with increased responsiveness to CCL3 [20]. 
Understanding the recruitment and trafficking of monocytes and tissue macrophages provide insight into the regulatory mechanisms guiding these cell populations. While monocytes are recruited from the circulation to mount a localized or systemic immune response, alveolar macrophages are, by definition, resident in the tissue and provide a localized immune response. This manuscript details the expression and functional significance of receptors for the C-C chemokines CCL2 and CCL3 on peripheral blood monocytes and alveolar macrophages.

\section{Methods}

\section{Antibodies and reagents}

All commercially available primer pairs, antibodies and recombinant proteins were purchased from R\&D Systems (Minneapolis, MN). PE-Cy5.5 labeled goat F(ab')2 antimouse IgG $(\mathrm{H}+\mathrm{L})$ was purchased from Caltag Laboratories (Burlingame, $\mathrm{CA}$ ).

\section{Peripheral blood monocyte and alveolar macrophage cell isolation}

Human monocytes and alveolar macrophages were isolated from healthy normal, non-smoking volunteers. All human samples were obtained through an institutional IRB-approved human subject protocol (OSU 1978H0059), after obtaining written informed consent from all participants. Alveolar macrophages were obtained from bronchoalveolar lavage fluid and washed three times in RPMI before use. Peripheral blood monocytes were obtained by negative isolation using a Monocyte Isolation Kit (Miltenyi Biotech, Auburn, CA) according to the manufacturer's protocol. The recommended isolation buffer was altered to contain $0.5 \%$ human serum albumin and 2 mM EDTA. With the exception of microarray studies, all experiments utilized matched pairs of monocytes and alveolar macrophages from the same donor.

\section{Microarray analysis}

Gene expression analysis was performed using Affymetrix U95Av2 gene arrays, according to the manufacturer's protocols. Ten micrograms of total RNA was isolated by the Trizol method, and purified using the Qiagen RNeasy kit (Qiagen, Valencia, CA). Double stranded cDNA was synthesized using an oligo-d(T) ${ }_{24}$ primer (GenSet Oligos, San Diego, CA) and cDNA synthesis kit (Invitrogen, Carlsbad, CA). cRNA was transcribed with a Bio-Array High-Yield RNA Transcript Labeling Kit (T7) (Enzo Diagnostics, Farmingdale, NY) and hybridized to the gene array in the Davis Heart \& Lung Research Institute (DHLRI) Genetics/ Microarray Core Facility. All gene chip data analysis was performed in the DHLRI Bioinformatics/Computational Biology (BCB) Core using Data Mining Tool (Affymetrix, Santa Clara, CA) and Microarray Suite 5.0 (Affymetrix, Santa Clara, CA) software.

\section{Reverse transcriptase PCR}

Total RNA was extracted by the Trizol method (Invitrogen, Carlsbad, CA) and single-stranded cDNA synthesized using a cDNA synthesis kit (Invitrogen, Carlsbad, CA). Commercially available PCR primers for human CCR1, CCR2, and CCR5 were utilized in a two-gene multiplex reaction with GAPDH primers added as a loading control. The PCR reaction consisted of 30 cycles at $94^{\circ} \mathrm{C}$ for $45 \mathrm{~s}$ for denaturing, $55^{\circ} \mathrm{C}$ for $45 \mathrm{~s}$ for annealing, and $72^{\circ} \mathrm{C}$ for $45 \mathrm{~s}$ for extension, according to the manufacturer's protocol. The PCR products were separated on a $2 \%$ agarose gel and stained with ethidium bromide then photographed and analyzed using Bandleader Application Version 3.00 (Magnitec, Tel Aviv, Israel). PCR bands were predicted at 201 bp (CCR1), 406 bp (CCR2), 459 bp (CCR5) and/or 576 bp (GAPDH). Densitometric values are always presented as a ratio of chemokine receptor band intensity to GAPDH band intensity.

\section{Flow cytometric analysis}

In preparation for flow cytometric analysis, freshly isolated peripheral blood monocytes and alveolar macrophages were placed in a buffer solution consisting of 100 $\mu \mathrm{g} / \mathrm{ml}$ human IgG (Jackson Immuno Research, West Grove, PA) in sterile PBS, for 10 minutes to block nonspecific binding. All subsequent steps were also carried out in this blocking buffer. Primary antibodies $(1 \mu \mathrm{g} / \mathrm{ml}$ for monocytes and $10 \mu \mathrm{g} / \mathrm{ml}$ for alveolar macrophages, to overcome autofluorescence) to CCR1 (clone 53504.111), CCR2 (clone 48607), CCR5 (clone 45502) and an $\operatorname{IgG}_{2 \mathrm{~b}}$ isotype control (clone name) were incubated with the freshly isolated cells for 45 minutes on ice, followed by washing and the addition of a tandem PE-Cy5 labeled goat $\mathrm{F}\left(\mathrm{ab}^{\prime}\right) 2$ anti-mouse IgG $(\mathrm{H}+\mathrm{L})$ (clone 20116.11) for 30 minutes on ice, in a protocol modified from Viksman, et al [35]. After a final wash, all cells were fixed with $10 \%$ buffered formalin (Fisher Scientific, Pittsburgh, PA) prior to analysis. Cytometric analysis was performed using a FACSCalibur flow cytometer (BD Biosciences, San Jose, CA).

\section{Migration assays}

A 48-well chemotaxis chamber (Neuroprobe, Rockville $\mathrm{MD}$ ) was used for all chemotaxis assays. Monocytes and all tested agents were treated with $10 \mu \mathrm{g} / \mathrm{ml}$ Polymyxin B (Calbiochem, San Diego, CA) to inhibit residual endotoxin contamination. Recombinant human CCL2, CCL3, or fMLP was loaded into the bottom well at the appropriate concentrations, and $4.5 \times 10^{4}$ monocytes or alveolar macrophages were added to the upper chamber. The chamber was incubated at $37^{\circ} \mathrm{C}$ with $5 \% \mathrm{CO}_{2}$ for $90 \mathrm{~min}$ utes. Monocyte chemotaxis was measured on a 5 -micron pore polycarbonate filter, and alveolar macrophages chemotaxis on an 8-micron pore polycarbonate filter (Osmonics, Inc. Minnetonka, MN). The filters were 
removed, fixed and stained in Diff-quik. Triplicate wells for each condition were counted under a high power $(40 \times)$ lens. Counts represent the cells remaining on the side away from the original cell suspension after removal from the chamber. These represent the cells caught "intransit" after having migrated through the membrane and to the other side, but before detachment and falling into solution on the opposite side of the membrane. At least five fields were counted per well and 15 total fields were counted per condition, in a blinded manner. Results were reported as the average number of cells per high-powered field for each condition. For experiments utilizing CCR5 blocking antibodies, prior to use in the migration assay, 1 $\mu \mathrm{g} / \mathrm{ml}$ anti-CCR5 antibody (clone 45531 ) or isogenic control IgG was incubated with the cells for 30 minutes then washed. After washing, the cells were used in the migration assay in the same manner as untreated cells.

\section{Statistical analyses}

Statistical analyses were performed using ANOVA with Tukey's post-hoc analysis on Minitab software (State College, PA). Data is presented as the mean \pm SEM.

\section{Results and discussion}

Alveolar macrophages do not express CCR2

Previous studies found CCR2 expression reduced in monocytes during in vitro differentiation $[19,20]$ Affymetrix microarray gene expression analysis indicated that the
CCL2 Receptor B (CCR2B; accession number U03905) was suppressed in alveolar macrophages compared to peripheral blood monocytes (Figure 1a). To verify gene array results, we performed reverse transcriptase PCR using monocyte and alveolar macrophages from additional matched donors and confirmed that mRNA for CCR2 is expressed at higher levels in peripheral blood monocytes than in alveolar macrophages (Figure 1b).

After finding differences in CCR2 mRNA expression, we correlated RNA expression with surface CCR2 expression on human monocytes and alveolar macrophages from the same donor. Using flow cytometric analysis, freshly isolated peripheral blood monocytes expressed the chemokine receptor CCR2 (Figure 2a), while alveolar macrophages did not (Figure 2b). There was significant expression of CCR2 on the surfaces of peripheral blood monocytes but not on alveolar macrophages (Figure 2c).

\section{Alveolar macrophages do not migrate toward CCL2 in a migration assay}

To establish that differences in CCR2 expression had functional consequences, freshly isolated peripheral blood monocytes and alveolar macrophages were assayed for migration to CCL2. Using in vitro migration assays, freshly isolated peripheral blood monocytes migrated toward rhCCL2 in a dose-dependent manner (Figure 3, filled bars), while alveolar macrophages from the same subjects

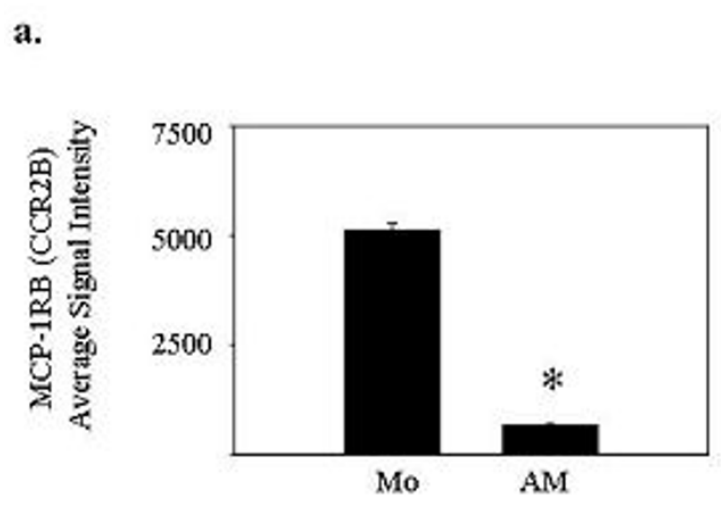

b.

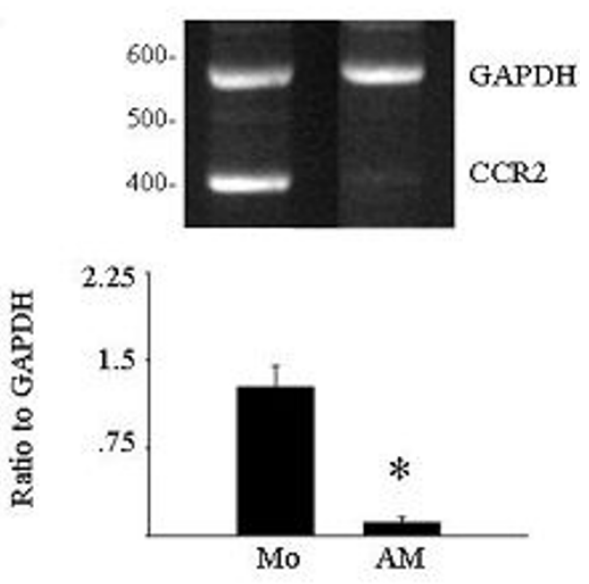

\section{Figure I}

Alveolar macrophages express less CCL2R/CCR2 RNA than peripheral blood monocytes. Using $10 \mu g$ of total RNA extracted from freshly isolated peripheral blood monocytes or alveolar macrophages, single stranded cDNA was synthesized and subjected to microarray analysis $(n=2)$ or 30 cycles of multiplex PCR using primers for CCR2 and GAPDH. Affymetrix microarray analysis indicated that a) alveolar macrophages express less CCL2RB (HG-U95Av2 39937 at, Accession No. U03905) than peripheral blood monocytes (*p < 0.05). b) Reverse transcriptase PCR for CCR2 confirmed these results. The bands shown in (b) are representative of 3 independent experiments from matched donors different than those used in (a), and the corresponding graph shows the ratio of CCR2 to GAPDH control band intensity by densitometry, averaged over the three donors \pm SEM $\left({ }^{*} \mathrm{p}<0.05\right.$ for CCR2 expression in alveolar macrophages compared to monocytes from the same donors). 
a.

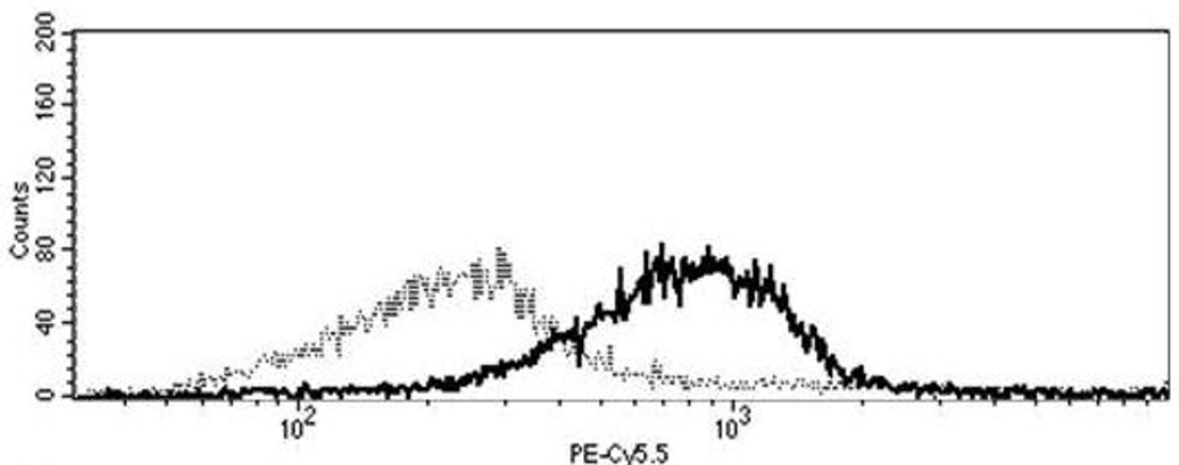

b.

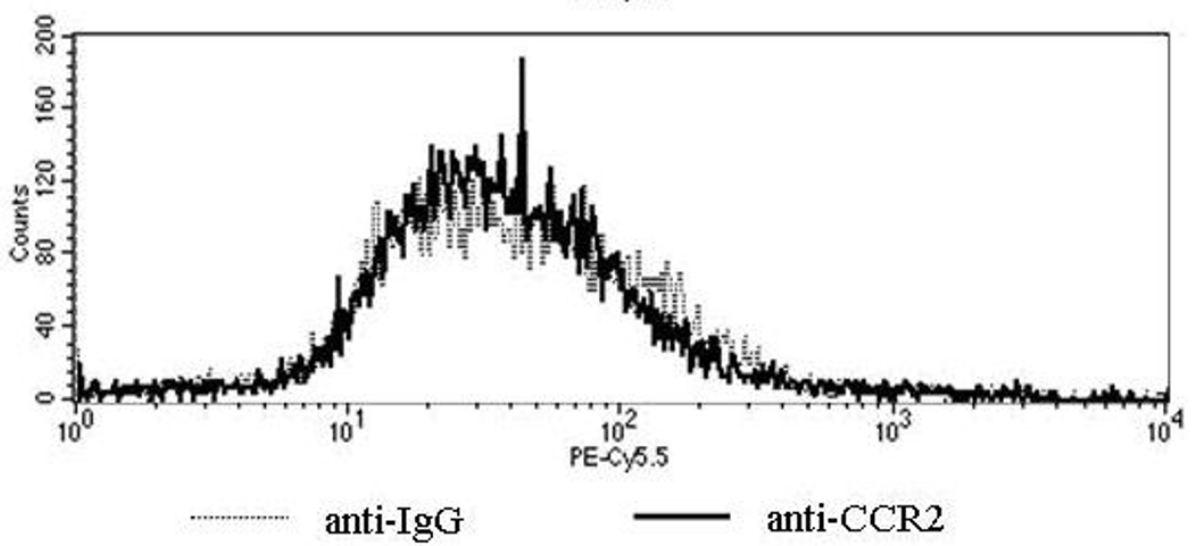

c.

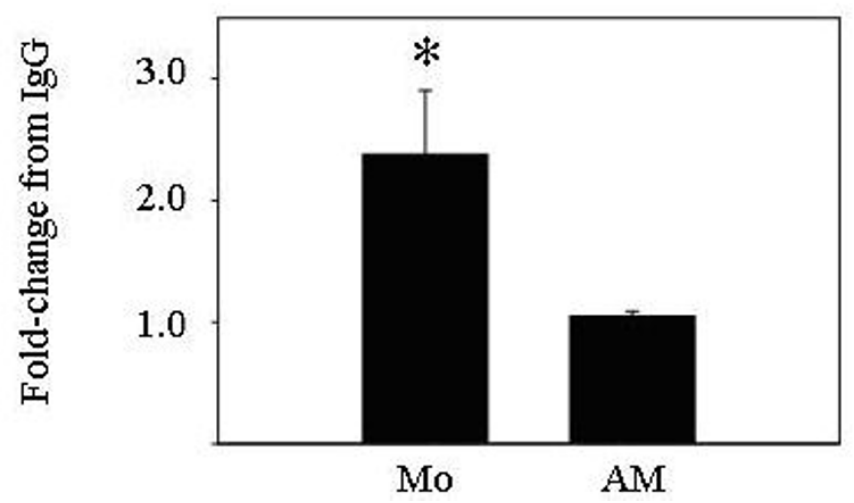

\section{Figure 2}

CCR2 surface protein is expressed at lower levels in alveolar macrophages compared to freshly isolated blood monocytes. (a) Monocytes $\left(5 \times 10^{5}\right.$ per condition) and (b) alveolar macrophages $\left(5 \times 10^{5} /\right.$ condition) were isolated from the same donor and subjected to flow cytometric staining for CCR2 (solid line). (c) The average fold increase in CCR2 median fluorescence over isogenic $\lg G$ was $2.64 \pm 0.48$ for monocytes $\left({ }^{*} p<0.05\right)$ and $1.12 \pm 0.10$ for alveolar macrophages $(p>0.05)$ for three independent experiments. Ig $\mathrm{G}$ isotype controls are represented by dashed lines.

only showed a minor response at the highest tested dose of CCL2 (Figure 3, open bars). In all migration assays used in this study, $5 \mu \mathrm{m}$ membrane pores were utilized for monocyte assays, and $8 \mu \mathrm{m}$ pores for AM assays, to account for the larger size of the AM's.
There were marked differences in the number of alveolar macrophages $(7.5 \pm 0.4$ cells/HPF) compared to blood monocytes $(77.9 \pm 3.7$ cells/HPF) migrating to CCL2 at the highest tested dose of the chemokine. The lack of chemotaxis was not due to an intrinsic defect in macro- 


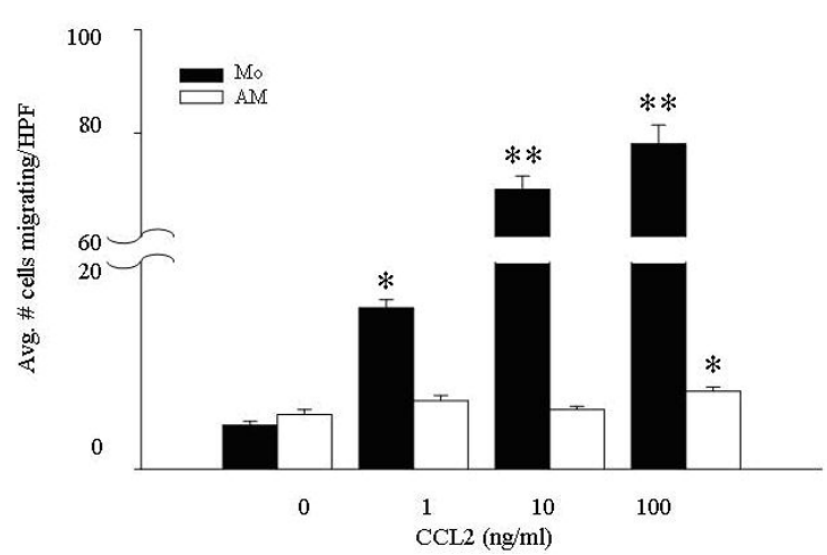

Figure 3

CCL2 preferentially recruits peripheral blood monocytes compared to alveolar macrophages in a migration assay. Freshly isolated monocytes and alveolar macrophages (4.5 × 104/condition) were subjected to a migration assay using increasing concentrations of rhCCL2 $(\mathrm{I}-100 \mathrm{ng} / \mathrm{ml})$ as the chemoattractant. Monocyte migration (filled bars) was significantly different from non-stimulated cells at all tested concentrations of CCL2 (*p $<0.0$ I; **p $<$ $0.00 \mathrm{I}$ ), while alveolar macrophage chemotaxis (open bars) was only different from non-stimulated cells at $100 \mathrm{ng} / \mathrm{ml}$ of CCL2 $\left(*_{p}<0.01\right)$. The mean of six independent experiments \pm SEM are shown.

phage chemotaxis as alveolar macrophages responded to CCL3 (Figure 4) and fMLP (data not shown).

\section{Peripheral blood monocytes and alveolar macrophages} are responsive to CCL3 in a migration assay

To confirm that alveolar macrophages recovered from the lungs of normal volunteers functioned normally, these cells were next assayed for chemotaxis toward CCL3. Freshly isolated peripheral blood monocytes and alveolar macrophages from the same subjects both showed dosedependent migration toward rhCCL3 (Figure 4).

In all experiments, alveolar macrophages migrated less vigorously than monocytes from the same donor even though equal numbers of cells from the same donors were used in each experiment. Both peripheral blood monocytes and alveolar macrophages responded maximally to $10 \mathrm{ng} / \mathrm{ml}$ CCL3. Again, there was a noticeable disparity in the number of monocytes versus alveolar macrophages migrating; while $77.2 \pm 3.4$ monocytes/high powered field migrated to $10 \mathrm{ng} / \mathrm{ml}$ CCL3, only $13.0 \pm 0.8$ alveolar macrophages migrated to this concentration of the chemokine. The difference in migration responses likely reflects the specialized functions of circulating versus tissue-residing immune cells.

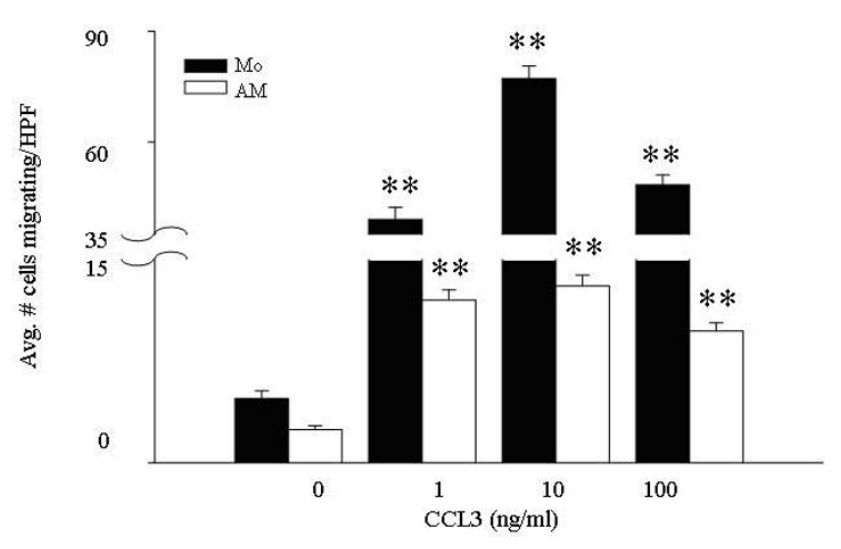

Figure 4

CCL3 is a chemoattractant for both peripheral blood monocytes and alveolar macrophages. Freshly isolated monocytes and alveolar macrophages $\left(4.5 \times 10^{4}\right.$ per condition) were subjected to migration assays using increasing concentrations of rhCCL3 as the chemoattractant. Monocytes (filled bars) and alveolar macrophages (open bars) responded in a dose-dependent manner to CCL3 (I-I00 ng/ $\mathrm{ml}$ ). Compared to unstimulated cells, cellular migration was significant $(* * p<0.001)$ at all CCL3 concentrations tested, for both cell types. Additionally, the average number of migrating alveolar macrophages (maximal response $=13.0 \pm$ 0.8 migrating cells per high-powered field at $10 \mathrm{ng} / \mathrm{ml} \mathrm{CCL3)}$ was 4-6-fold less than the average number of migrating monocytes (maximal response $=77.2 \pm 3.4$ migrating cells per high-powered field, at $10 \mathrm{ng} / \mathrm{ml} \mathrm{CCL3})(p<0.001$ when comparing monocyte and alveolar macrophage migration at every concentrations of CCL3). The mean of six independent experiments \pm SEM are shown.

\section{Peripheral blood monocytes and alveolar macrophages differentially express surface protein for the CCL3 receptors, CCRI and CCR5}

In contrast to CCL2, which predominantly binds CCR2, CCL3 binds both CCR1 and CCR5. Surface protein expression of these receptors on monocytes and alveolar macrophages was assessed using flow cytometry. While freshly isolated peripheral blood monocytes expressed CCR1 on the cell surface (Figure 5a, c), alveolar macrophages did not (Figure 5b, c). In contrast, no CCR5 expression was detected on the surface of peripheral blood monocytes (Figure 5d, f), while alveolar macrophages did express CCR5 surface protein (Figure 5e, f).

\section{Use of CCR5 blocking antibodies abrogates CCL3-induced chemotaxis in alveolar macrophages}

To verify that surface expression of CCR 1 and CCR 5 predicted biological responsiveness to CCL3 in these cells, we next examined the effect of anti-CCR5 blocking antibodies on CCL3-induced migration. Consistent with a lack of CCR5 surface expression on monocytes, anti-CCR 5 blocking antibodies did not reduce monocyte chemotaxis in 
a.

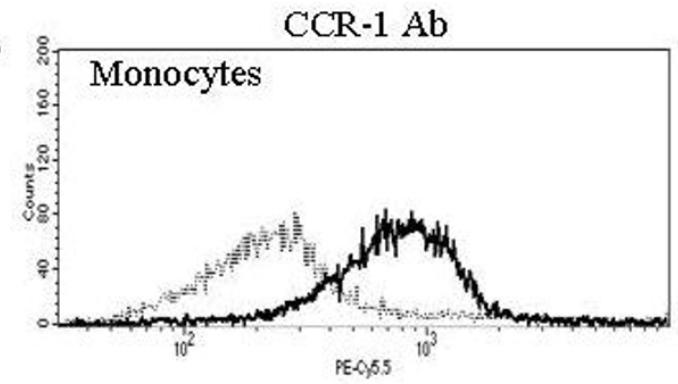

b.

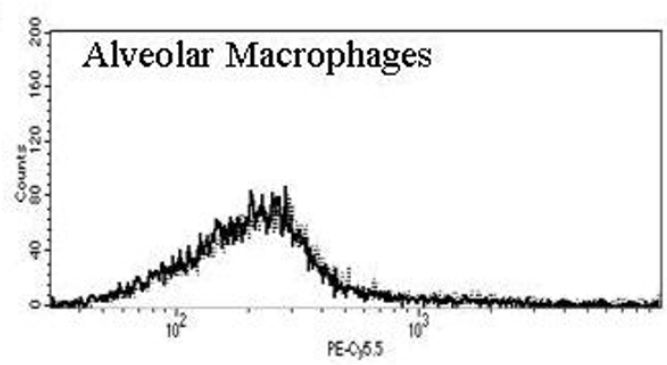

c.

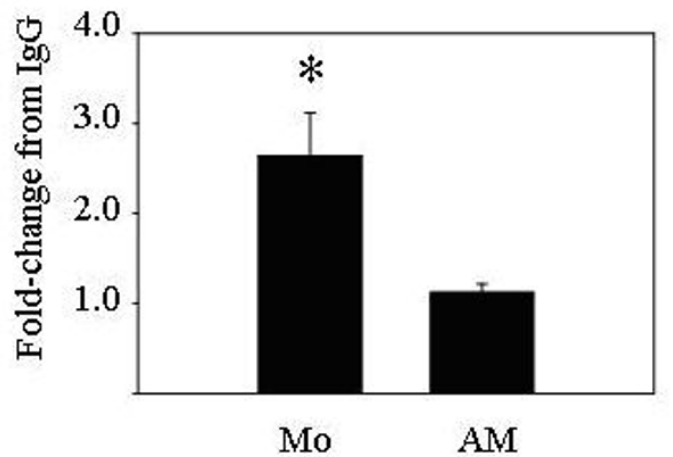

d.

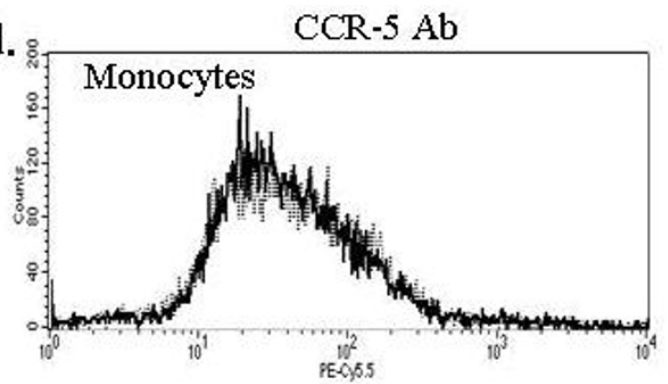

e.

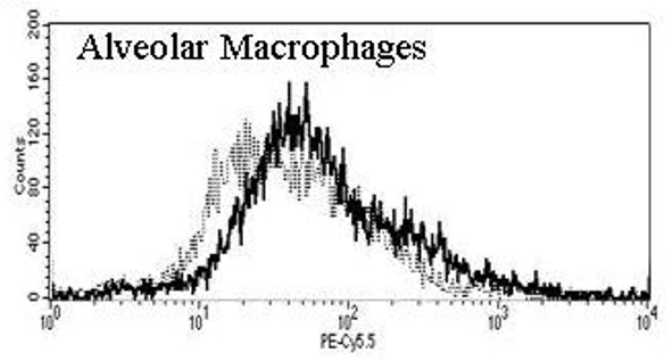

f.

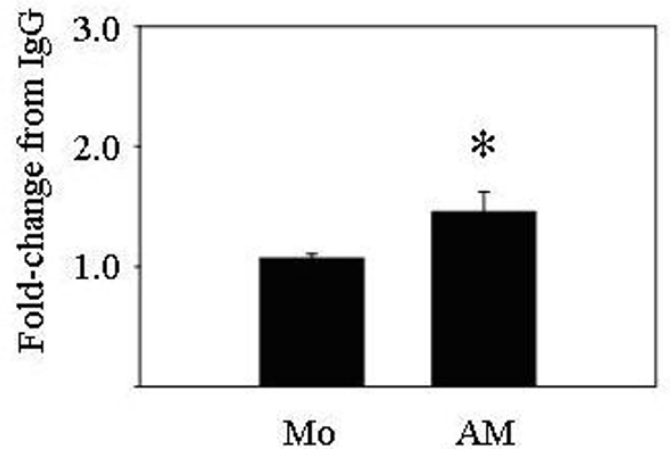

\section{Figure 5}

Peripheral blood monocytes and alveolar macrophages differentially express the CCL3 receptors CCRI and CCR5. Freshly isolated monocytes and alveolar macrophages $(5 \times 105 /$ condition) were assayed for surface expression of CCRI (left panels) and CCR5 (right panels) using flow cytometry. (a) Monocytes expressed CCRI but (d) not CCR5. For monocytes, the average fold-increase in median fluorescence over IgG when staining for (c) CCRI was $2.37 \pm 0.53\left({ }^{*} \mathrm{p}<0.05\right.$ versus $\lg G$ controls), and when staining for ( $f$ ) CCR5 was $I .07 \pm 0.04$ ( $p>0.05$ versus $\lg G$ controls). Alveolar macrophages expressed (d) CCR5, but not (b) CCRI. For alveolar macrophages, the average fold-increase in mean fluorescence over IgG when staining for (c) CCRI was I.04 \pm 0.04 ( $p>0.05$ versus IgG controls), and when staining for (f) CCR5 was I.45 \pm 0.17 ( $* p$ $<0.05$ versus $\lg$ controls). $\lg \mathrm{g}$ isotype controls are shown (dashed lines). Data are representative of three independent experiments and graphs represent mean \pm SEM.

response to CCL3 compared to isogenic control IgG (Figure 6a). In contrast, anti-CCR5 blocking antibodies reduced the chemotaxis of alveolar macrophages at all tested doses of CCL3 (Figure 6b). CCR1 blocking antibodies are not commercially available.

\section{Discussion}

Chemokines are small proteins that regulate cellular trafficking $[36,37]$. These proteins are constitutively released to maintain homeostatic conditions or are inducible under inflammatory conditions. To date, there are 47 identified chemokines that bind at least 18 different receptors. The capability of one receptor to bind multiple chemokines demonstrates the complexity and redundant function of this protein family. However, the expression of the receptor and the production of the chemokine within the local tissue must coincide to elicit a response. Many chemokines have overlapping function including 
a.

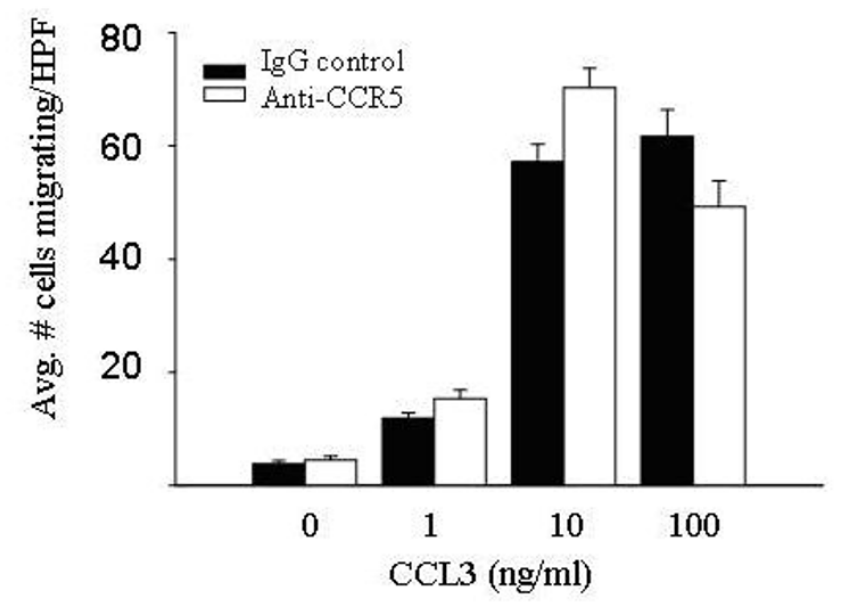

b.

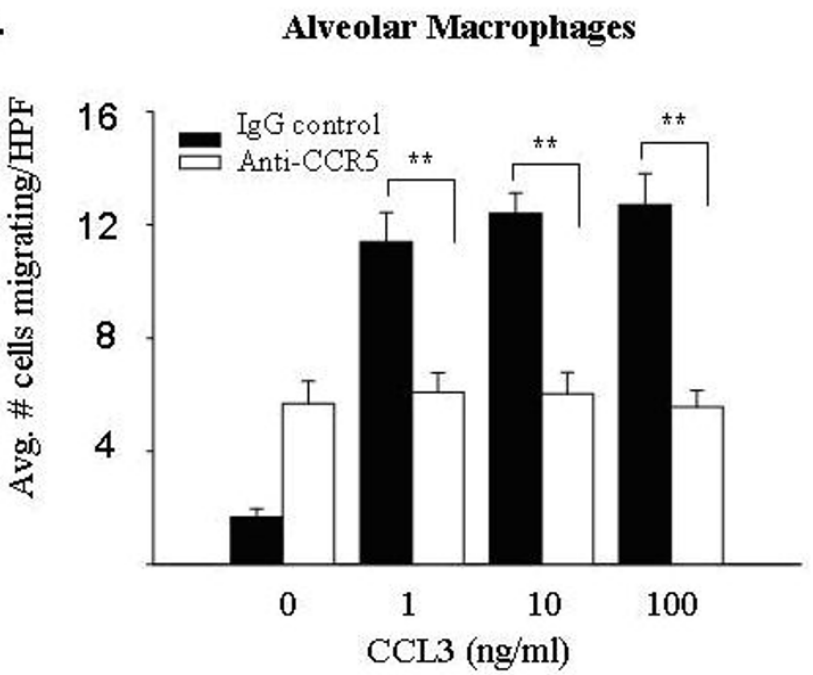

Figure 6

Blocking antibodies to CCR5 decrease CCL3-induced chemotaxis in alveolar macrophages, but not fresh monocytes. Freshly isolated monocytes and alveolar macrophages (4.5 × $104 /$ condition) were pre-incubated with I $\mu$ g/ml CCR5 blocking antibodies and subjected to a migration assay using CCL3 $(\mathrm{I}-100 \mathrm{ng} / \mathrm{ml})$ as the chemoattractant. The addition of anti-CCR5 antibodies did not significantly alter monocyte chemotaxis (left panel) at any concentration of CCL3 compared to the IgG control ( $p>0.05$ at all concentrations). In contrast, the addition of anti-CCR5 antibodies decreased CCL3-induced alveolar macrophage chemotaxis (right panel) at all tested concentrations of CCL3 (**p $<0.00 \mathrm{I})$. Results represent mean \pm SEM for three independent studies.

CCL2 and CCL3. Both recruit monocytes to areas of inflammation $[3,21]$, but via interactions with different receptors. In general, the loss of either the chemokine or receptor tends to have a minimal effect. However, recent studies demonstrated that in mice the loss of both CXCL12 and its receptor CXCR4 is embryonic lethal [36]. These observations suggest that there may also be nonredundant functions of a chemokine/receptor pair. This may not be true for all combinations; in particular the CCL2/CCR2 double knock-out mouse is viable $[38,39]$. Similar to the CCR2-/- mouse, the CCL2/CCR2 double knock-out mouse is unable to clear parasitic infections [39] despite higher than normal interferon- $\gamma$ production than the CCR2 deficient mouse. Further investigations and the generation of additional chemokine ligand/receptor double knockout mice will better elucidate the nonoverlapping functions of these molecules.

This study evaluated the regulation of monocyte and alveolar macrophage recruitment in response to the chemokines CCL2 and CCL3. We report that freshly isolated alveolar macrophages did not express CCR2, and were unresponsive to CCL2 as a chemotactic stimulus. In contrast, this study and others demonstrated that freshly isolated peripheral blood monocytes expressed CCR2 and respond to CCL2 [19]. Taken together, these data suggest that pulmonary CCL2 primarily targets circulating periph- eral blood monocytes for recruitment and has little effect on alveolar macrophages.

In contrast to selective monocyte recruitment by CCL2, circulating monocytes and freshly isolated alveolar macrophages both migrated toward CCL3, albeit using different surface receptors. To respond to CCL3, monocytes expressed CCR1, while alveolar macrophages expressed CCR5. Interestingly, expression of CCR1 and CCR5 appeared to be regulated at a post-transcriptional level, as both cell types expressed similar levels of RNA for both CCR1 and CCR5 (data not shown). These data suggest that lung inflammation mediated by CCL3 predictably involves both monocytes and alveolar macrophages. Given the different properties of CCL2 and CCL3, the preferential recruitment of monocytes and/or alveolar macrophages could have profound implications on the host response to inflammatory stimuli.

This study extends previous work that used monocytederived macrophages (MDM) as surrogates for native tissue macrophages and demonstrates that freshly isolated native alveolar macrophages did not express CCR2. These data suggest that decreased expression of CCR2 is a manifestation of cellular differentiation. The lack of CCR2 expression has important implications in understanding CCL2-mediated inflammation, as resident alveolar mac- 
rophages, like monocyte-derived macrophages, are unresponsive to this chemotactic stimulus.

Previous investigators have examined the effects of CCL2 on monocytes and macrophages, without differentiating the two types of cells. Some papers use the term "monocyte/macrophage" rather than identifying each cell separately [40]. For example, Lu, et al were surprised that mice genetically deficient in CCL2 did not have obvious defects in clearing M. tuberculosis infection [4], a response that is macrophage-dependent. In the context of this report, we speculate that because alveolar macrophages lack CCR2, it is not surprising that CCL2 has little effect in regulating these cells.

In contrast to the selective expression of the CCL2 receptor CCR2, both monocytes and alveolar macrophages express receptors for CCL3. Interestingly, the specific receptor expressed by each cell type appears different and comparatively more monocytes than alveolar macrophages migrate toward a given dose of CCL3. The reason for this difference in migration of monocytes versus macrophages toward CCL3 is not clear. Quantitatively, monocytes migrate to CCL3 6-fold better than alveolar macrophages from the same volunteers. One possible explanation lies in the intrinsic properties of these cells; monocytes circulate through the peripheral blood and are, by definition, mobile. Macrophages, on the other hand, are resident tissue cells, and therefore may be inherently less mobile than their monocyte counterparts.

Others have reported that fMLP recruits macrophages [41]. This chemotactic property was preserved in our freshly isolated resident alveolar macrophages (data not shown). The ability of macrophages to migrate upon selective stimuli begins to uncover mechanisms of local immune surveillance of these cells.

Curiously, our data indicates that alveolar macrophages respond to CCL3 through CCR5, and do not, as is found for monocyte-derived macrophages, express the only other known CCL3 receptor, CCR1. Blockade of CCR5 completely abrogated CCL3-induced chemotaxis in alveolar macrophages in this study, demonstrating that this chemokine receptor was regulating recruitment. Peripheral blood monocytes, on the other hand, responded to CCL3 via CCR1, as these cells did not express CCR5, and were not affected by blockade of CCR5. Although blocking antibodies to CCR1 are not commercially available, we would hypothesize that CCR1 blockade would selectively influence the migration of peripheral blood monocytes to CCL3. The differential expression of CCR1 and CCR5 may discern yet another level of regulation in lung homeostasis. Studies are underway in our laboratory to determine if differences in expression of CCR1 and CCR5 are responsible for the discrepancies in CCL3-induced migratory capabilities of monocytes and alveolar macrophages.

\section{Conclusion}

These data provide insight into the biochemical mechanisms of mononuclear phagocyte trafficking to the lung, in lung inflammation and immune responses. Our data confirms previous studies indicating that blood monocytes express CCR2 and migrate towards CCL2, and the data presented here demonstrate that alveolar macrophages do not express this receptor, nor respond to CCL2. In contrast, both monocytes and alveolar macrophages respond to CCL3, although via different cell surface receptors.

In summary, data presented in this manuscript suggests that inhibiting CCL2 or CCR2 would specifically reduce monocyte-mediated inflammation and following, that CCL2 selectively drives monocyte recruitment. This data also uncovers possibilities for novel drug applications to regulate host inflammation.

\section{Competing interests}

The author(s) declare that they have no competing interests.

\section{Authors' contributions}

JMO carried out the microarray analyses, RT-PCR and flow cytometry, performed statistical analyses and drafted the manuscript. NAA performed migration assays and related statistical analyses. JML assisted with data acquisition and analysis for molecular and cellular studies. MGH assisted with manuscript preparation. CBM conceived of the study and participated in its design and coordination. All authors read and approved the final manuscript.

\section{Acknowledgements}

This work was funded by NIH grants: R0IHL63800, ROIHL66I08, ROIHL67I 76 and POIHL702945454; and the Johnie Walker Murphy Career Investigator Award (National American Lung Association) and Kelly Clark Memorial Fund (American Lung Association of Ohio).

\section{References}

I. Matsushima K, Larsen CG, DuBois GC, Oppenheim JJ: Purification and characterization of a novel monocyte chemotactic and activating factor produced by a human myelomonocytic cell line. J Exp Med 1989, 169:|485-1490.

2. Rollins BJ: JE/MCP-I: an early-response gene encodes a monocyte-specific cytokine. Cancer Cells 1991, 3:5 I7-524.

3. Baggiolini M, Dewald B, Moser B: Human chemokines: an update. Annu Rev Immunol 1997, 15:675-705.

4. Lu B, Rutledge BJ, Gu L, Fiorillo J, Lukacs NW, Kunkel SL, North R, Gerard C, Rollins BJ: Abnormalities in monocyte recruitment and cytokine expression in monocyte chemoattractant protein I-deficient mice. J Exp Med 1998, 187:60I-608.

5. Baran CP, Opalek JM, McMaken S, Newland CA, O'Brien JM, Hunter MG, Bringardner BD, Monick MM, Brigstock DR, Stromberg PC, Hunninghake GW, Marsh CB: Important Roles for Macrophage Colony-stimulating Factor, CC Chemokine Ligand 2, and 
Mononuclear Phagocytes in the Pathogenesis of Pulmonary Fibrosis. Am J Respir Crit Care Med 2007, I 76(I):78-89.

6. Fuentes ME, Durham SK, Swerdel MR, Lewin AC, Barton DS, Megill JR, Bravo R, Lira SA: Controlled recruitment of monocytes and macrophages to specific organs through transgenic expression of monocyte chemoattractant protein-I. J Immunol 1995, I 55:5769-5776.

7. Huang D, Tani M, Wang J, Han Y, He TT, Weaver J, Charo IF, Tuohy VK, Rollins BJ, Ransohoff RM: Pertussis toxin-induced reversible encephalopathy dependent on monocyte chemoattractant protein-I overexpression in mice. I Neurosci 2002, 22:10633-10642.

8. Chen Y, Hallenbeck JM, Ruetzler C, Bol D, Thomas K, Berman NE, Vogel SN: Overexpression of monocyte chemoattractant protein $I$ in the brain exacerbates ischemic brain injury and is associated with recruitment of inflammatory cells. J Cereb Blood Flow Metab 2003, 23:748-755.

9. Mack M, Cihak J, Simonis C, Luckow B, Proudfoot AE, Plachy J, Bruhl $H$, Frink M, Anders HJ, Vielhauer V, Pfirstinger J, Stangassinger M, Schlondorff D: Expression and characterization of the chemokine receptors CCR2 and CCR5 in mice. J Immunol 200I, 166:4697-4704.

10. Charo IF, Myers SJ, Herman A, Franci C, Connolly AJ, Coughlin SR: Molecular cloning and functional expression of two monocyte chemoattractant protein I receptors reveals alternative splicing of the carboxyl-terminal tails. Proc Natl Acad Sci USA 1994, 9 I:2752-2756.

II. Wong LM, Myers SJ, Tsou CL, Gosling J, Arai H, Charo IF: Organization and differential expression of the human monocyte chemoattractant protein I receptor gene. Evidence for the role of the carboxyl-terminal tail in receptor trafficking. J Biol Chem 1997, 272:1038-1045.

12. Kurihara T, Warr G, Loy J, Bravo R: Defects in macrophage recruitment and host defense in mice lacking the CCR2 chemokine receptor. J Exp Med 1997, I86: I757-I762.

13. Reid S, Ritchie A, Boring L, Gosling J, Cooper S, Hangoc G, Charo IF, Broxmeyer HE: Enhanced myeloid progenitor cell cycling and apoptosis in mice lacking the chemokine receptor, CCR2. Blood 1999, 93:1524-1533.

14. Moore B, Murray L, Das A, Wilke CA, Wilke CA, Herrygers, Toews GB: The role of CCLI 2 in the recruitmen of fibrocytes and lung fibrosis. Am J Respir Cell Mol Biol 2005, 35:175-I8I.

15. Boring L, Gosling J, Chensue SW, Kunkel SL, Farese RV Jr, Broxmeyer $\mathrm{HE}$, Charo IF: Impaired monocyte migration and reduced type I (Th I) cytokine responses in C-C chemokine receptor 2 knockout mice. J Clin Invest 1997, 100:2552-256I.

16. Moore BB, Paine R III, Christensen PJ, Moore TA, Sitterding S, Ngan R, Wilke CA, Kuziel WA, Toews GB: Protection from pulmonary fibrosis in the absence of CCR2 signaling. J Immunol 200I, 167:4368-4377.

17. Ikeda U, Matsui K, Murakami Y, Shimada K: Monocyte chemoattractant protein-I and coronary artery disease. Clin Cardiol 2002, 25: $143-147$

18. Mahad DJ, Ransohoff RM: The role of MCP-I (CCL2) and CCR2 in multiple sclerosis and experimental autoimmune encephalomyelitis (EAE). Semin Immunol 2003, 15:23-32.

19. Fantuzzi L, Borghi P, Ciolli V, Pavlakis G, Belardelli F, Gessani S: Loss of CCR2 expression and functional response to monocyte chemotactic protein (MCP-I) during the differentiation of human monocytes: role of secreted MCP-I in the regulation of the chemotactic response. Blood 1999, 94:875-883.

20. Kaufmann A, Salentin R, Gemsa D, Sprenger H: Increase of CCR I and CCR5 expression and enhanced functional response to MIP-I alpha during differentiation of human monocytes to macrophages. J Leukoc Biol 200I, 69:248-252.

21. Sherry B, Tekamp-Olson P, Gallegos C, Bauer D, Davatelis G, Wolpe $S D$, Masiarz F, Coit D, Cerami A: Resolution of the two components of macrophage inflammatory protein $I$, and cloning and characterization of one of those components, macrophage inflammatory protein I beta. J Exp Med 1988, 168:225I-2259.

22. Menten $P$, Wuyts A, Van Damme J: Macrophage inflammatory protein- I. Cytokine Growth Factor Rev 2002, 13:455-48I.

23. Cook DN: The role of MIP-I alpha in inflammation and hematopoiesis. J Leukoc Biol 1996, 59:61-66.
24. Reape T], Groot PH: Chemokines and atherosclerosis. Atherosclerosis 1999, 147:213-225.

25. Koch AE, Kunkel SL, Shah MR, Fu R, Mazarakis DD, Haines GK, Burdick MD, Pope RM, Strieter RM: Macrophage inflammatory protein-I beta: a C-C chemokine in osteoarthritis. Clin Immunol Immunopathol I995, 77:307-3 I4.

26. Tanaka Y, Mine S, Figdor CG, Wake A, Hirano H, Tsukada J, Aso M, Fujii K, Saito K, van Kooyk Y, Eto S: Constitutive chemokine production results in activation of leukocyte function-associated antigen-I on adult T-cell leukemia cells. Blood 1998, 91:3909-3919.

27. Smith RE, Strieter RM, Zhang K, Phan SH, Standiford TJ, Lukacs NW Kunkel SL: A role for $\mathrm{C}-\mathrm{C}$ chemokines in fibrotic lung disease. J Leukoc Biol 1995, 57:782-787.

28. Hasegawa M, Sato S, Takehara K: Augmented production of chemokines (monocyte chemotactic protein-I (MCP-I), macrophage inflammatory protein-I alpha (MIP-Ialpha) and MIP-Ibeta) in patients with systemic sclerosis: MCP-I and MIP-Ialpha may be involved in the development of pulmonary fibrosis. Clin Exp Immunol 1999, I 17:159-165.

29. Murphy PM, Baggiolini M, Charo IF, Hebert CA, Horuk R, Matsushima $\mathrm{K}$, Miller LH, Oppenheim JJ, Power CA: International union of pharmacology. XXII. Nomenclature for chemokine receptors. Pharmacol Rev 2000, 52:145-176.

30. Baggiolini M: Chemokines and leukocyte traffic. Nature 1998, 392:565-568.

31. Richardson RM, Pridgen BC, Haribabu B, Snyderman R: Regulation of the human chemokine receptor CCRI. Cross-regulation by CXCRI and CXCR2. J Biol Chem 2000, 275(I3):920I-8.

32. Fraziano M, Cappelli G, Santucci M, Mariani F, Amicosante M, Casarini M, Giosue S, Bisetti A, Colizzi V: Expression of CCR5 is increased in human monocyte-derived macrophages and alveolar macrophages in the course of in vivo and in vitro Mycobacterium tuberculosis infection. AIDS Res Hum Retroviruses 1999 , I5:869-874

33. Carrington M, Dean M, Martin MP, O'Brien SJ: Genetics of HIV-I infection: chemokine receptor CCR5 polymorphism and its consequences. Hum Mol Genet 1999, 8: 1939-1945.

34. Hornung D, Bentzien F, Wallwiener D, Kiesel L, Taylor RN: Chemokine bioactivity of RANTES in endometriotic and normal endometrial stromal cells and peritoneal fluid. Mol Hum Reprod 200I, 7:163-168.

35. Viksman MY, Liu MC, Schleimer RP, Bochner BS: Application of a flow cytometric method using autofluorescence and a tandem fluorescent dye to analyze human alveolar macrophage surface markers. J Immunol Methods 1994, 172:17-24.

36. Colobran R, Pujol-Borrell R, Armengol MP, Juan M: The chemokine network. I/How the genomic organization of chemokines contains clues for deciphering their functional complexity. Clinical and Experimental Immunology 2007, 148:208-217.

37. Bajetto A, Bonavia R, Barbero S, Schnettini G: Characterization of chemokines and their receptors in the central nervous system; physiopathological implications. Journal of Neurochemistry 2002, 82: I3II-I329.

38. Kalkonde YV, Morgan WW, Sigala J, Maffi SK, Condello C, Kuziel W, Ahuja SS, Ahuja SK: Chemokines in the MPTP model of Parkinson's Disease: Absence of CCL2 and its receptor CCR2 does not protect against striatal neurodegeneration. Brain Research 2007, II 28: I-II.

39. Quinones MP, Estrada CA, Jiminez F, Martines H, Willmon O, Kuziel WA, Ahuja SK, Ahuja SS: CCL2-independent role of CCR2 in immune responses against Leishmania Major. Parasite Immunology 2007, 29:2II-217.

40. Maus U, von Grote K, Kuziel WA, Mack M, Miller EJ, Cihak J, Stangassinger M, Maus R, Schlondorff D, Seeger W, Lohmeyer J: The role of CC chemokine receptor 2 in alveolar monocyte and neutrophil immigration in intact mice. Am J Respir Crit Care Med 2002, 166:268-273.

4I. Fillion I, Ouellet N, Simard M, Bergeron Y, Sato S, Bergernon MG: Role of chemokines and formyl peiptdes in pneumococcal pneumonia-induced monocyte/macrophage recruitment. J Immunol 200I, 166:7353-736I. 